\title{
Article
}

\section{Public health outcome of Tuberculosis Cluster Investigations, England 2010- 2013}

Hamblion, E.L., Burkitt, A., Lalor, M.K., Anderson, L.F., Thomas, H.L., Abubakar, I., Morton, Stephen, Maguire, H. and Anderson, S.R.

Available at http://clok.uclan.ac.uk/29055/

Hamblion, E.L., Burkitt, A., Lalor, M.K., Anderson, L.F., Thomas, H.L., Abubakar, I., Morton, Stephen ORCID: 0000-0001-7122-0201, Maguire, H. and Anderson, S.R. (2019) Public health outcome of Tuberculosis Cluster Investigations, England 2010-2013. Journal of Infection, 78 (4). pp. 269-274. ISSN 0163-4453

It is advisable to refer to the publisher's version if you intend to cite from the work. http://dx.doi.org/10.1016/j.jinf.2018.12.004

For more information about UCLan's research in this area go to http://www.uclan.ac.uk/researchgroups/ and search for <name of research Group>.

For information about Research generally at UCLan please go to http://www.uclan.ac.uk/research/

All outputs in CLoK are protected by Intellectual Property Rights law, including Copyright law. Copyright, IPR and Moral Rights for the works on this site are retained by the individual authors and/or other copyright owners. Terms and conditions for use of this material are defined in the policies page.

\section{CLoK}

Central Lancashire online Knowledge www.clok.uclan.ac.uk

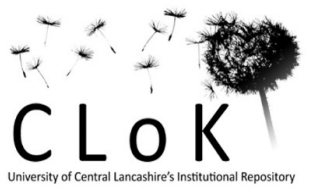


Public Health Outcome of Tuberculosis Cluster Investigations, England 20102013

E.L. Hamblion ${ }^{1}$, A. Burkitt' ${ }^{1}$, M.K. Lalor ${ }^{2}$, L.F. Anderson², H.L. Thomas ${ }^{2}$, I. Abubakar ${ }^{2,3}$, S. Morton ${ }^{4}$, H. Maguire $^{1,3}$, S.R. Anderson ${ }^{4}$ on behalf of the Public Health England TB Strain Typing Board

1. Field Epidemiology Services, Public Health England, UK

2. Centre for Infectious Disease Surveillance and Control, Public Health England, UK

3. Institute for Global Health, University College London, London, UK

4. Health Protection Services, Public Health England, UK

Corresponding author: Esther Hamblion, estherhamblion@hotmail.com

Key words - Tuberculosis, Cluster Investigations, Outbreaks, Public Health, Epidemiology

Running Title - A descriptive analysis of molecular strain-typed cluster investigations undertaken in England from 2010-2013

Take home message - TB molecular strain-typing and cluster investigation leads to additional public health action and saving of resources 


\section{Abstract}

Objectives: Tuberculosis(TB) is a serious re-emergent public health problem in the UK. In response to rising case incidence a National TB Strain-Typing Service based on molecular strain-typing was established. This facilitates early detection and investigation of clusters, targeted public health action, and prevention of further transmission. We review the added public health value of investigating molecular TB strain-typed(ST) clusters.

Methods: A structured questionnaire for each ST cluster investigated in England between 1 January 2010 and 30 June 2013 was completed. Questions related to epidemiological links and public health action and the perceived benefits of ST cluster investigation.

Results: There were 278 ST cluster investigations(Cls) involving 1882 TB cases. Cluster size ranged from 2 to 92 . Cls identified new epidemiological links in $36 \%$ of clusters; in $18 \%$ STs were discordant refuting transmission thought to have occurred. Additional public health action was taken following $23 \%$ of $\mathrm{Cl}$.

Conclusions: We found positive benefits of TB molecular ST and $\mathrm{Cl}$, in identifying new epidemiological links between cases and taking public health action and in refuting transmission and saving resources. This needs to be translated to a decrease in transmission to provide evidence of public health value in this low prevalence high resource setting. 


\section{Background}

Tuberculosis (TB) is a serious re-emergent public health problem in the United Kingdom (UK). Since the late 1980s the incidence of tuberculosis in England steadily increased to a peak of 15.6 per 100,000 in 2011 (1), higher than most western European countries (2) and nearly five times greater than in the United States (3). In response to this rising incidence and the UK Chief Medical Officer's TB Action Plan of 2004 which recommended developing molecular typing as a surveillance tool (4), a national prospective molecular strain typing service was established. The Tuberculosis Strain Typing Service (TB-STS) was therefore initiated in 2010, by Public Health England (PHE), as a key component in helping to control the spread of TB.

The PHE TB-STS aims to support TB control by facilitating early detection and subsequent epidemiological cluster investigation leading to targeted public health action. Although molecular typing services exist in a number of other countries including the United States of America, the Netherlands and Denmark $(5,6,7)$ the TB-STS in England is unique in that it was the first universal national prospective service using 24-loci mycobacterium interspersed repetitive units variable number tandem repeat (MIRU-VNTR) matched with epidemiological surveillance data for those diagnosed with TB (8).

As part of the TB-STS, clusters were investigated by PHE local public health specialists supported by National Health Service (NHS) clinical services staff. The aim of a cluster investigation was to identify epidemiological links between cases in order to prevent further transmission of that TB strain by undertaking enhanced public health action e.g. extended contact tracing to identify and treat additional cases of Latent Tuberculosis Infection (LTBI) and active TB disease (9).

We aim to describe the additional public health actions and perceived added public health value of investigating molecular TB strain-typed (ST) clusters to provide information for further development of the national TB-STS and future Whole Genome Sequencing (WGS) in England. We describe a study of TB cluster investigations (Cls) in England from January 2010 to June 2013 , the reasons why they were initiated, the frequency with which epidemiological links were found and the resulting actions undertaken. 


\section{Method}

\section{Cluster Identification and Investigation}

As part of the TB-STS in England molecular typing using 24-loci MIRU-VNTR was carried out on all initial TB culture-positive isolates at one of the three reference laboratories in England (8). Molecular information was matched to routinely collected case-based epidemiological information obtained from the PHE national Enhanced Tuberculosis Surveillance system (ETS) $(8,9)$. A decision to investigate a strain-typed cluster was based on pre-agreed criteria including size, geographical spread or inclusion of cases which had risk factors suggesting potential for higher risk or recent TB transmission (e.g. children, drug resistant cases) (9). $\mathrm{Cl}$ included review of hospital clinic records, and/or patient interviews and standardised $\mathrm{Cl}$ questionnaires. This information was reviewed to determine potential epidemiological links and if disease transmission had occurred (9). An incident control team may be established consisting of multidisciplinary experts to advise and determine the appropriate course of public health actions required (9).

\section{Data collection}

We developed a structured questionnaire, the TB-STS Cluster Investigation Outcome Form to be completed by public health staff who investigated a cluster at local, regional or national level between 1 January 2010 and 30 June 2013. Details recorded included geography and size of the cluster, reason for beginning the investigation (reached a threshold, risk factors identified or other), whether epidemiological links were known prior to molecular cluster information, whether new epidemiological links were found following molecular cluster information, what public health actions were taken, outcome of the $\mathrm{Cl}$ (probable or definite chain of transmission identified, or no apparent transmission, investigation ongoing or inconclusive), what factors may have contributed to the cluster, whether the molecular typing information was useful and whether it refuted previously suspected epidemiological links.

\section{Data entry}

We developed a Cluster Monitoring Database (CMD) in Microsoft Access. Data on all Cls being undertaken was entered together with data from the $\mathrm{Cl}$ Outcome Form after conclusion of the $\mathrm{Cl}$.

\section{Data management and analysis}

We performed data consistency checks on key variables from the $\mathrm{Cl}$ Outcome Form to ensure their validity. Any identified discrepancies were followed up with lead investigators. We created two new variables derived from information on the $\mathrm{Cl}$ Outcome Form: public health action taken prior to receipt of ST information, and public health action taken as a consequence of $\mathrm{Cl}$. Descriptive analysis was undertaken using Microsoft Excel and Stata 13.1. 


\section{Definitions}

A ST cluster was defined as two or more cases with indistinguishable 24-loci MIRU-VNTR in England (with at least one case with a complete 24-loci profile and others at least 23-loci typed). Local clusters were those where all members lived in a single Health Protection Team (HPT) area (there were 26 such teams in England); regional clusters were those where cases spanned two or more HPTs (though remained within a single region, of which there were nine); and national were those containing cases in more than one region.

Clusters were defined as small if they contained 2-4 cases, medium if contained 5-9 cases and large if contained ten or more cases.

Risk factors(RFs) suggesting potential for higher risk of or recent TB transmission included alcohol or drug misuse, history of or currently being homeless or in prison.

The threshold for investigation was set as five cases in a cluster in the same local HPT or ten cases across a region or nationally. Some clusters where cases had RFs may have been investigated when the cluster contained fewer than five cases.

Epidemiological links were recorded if cases were linked in time and place, and were categorised as known or possible links.

Known epidemiological links were recorded if;

- one case volunteered the name of another case whilst either was potentially infectious (had pulmonary TB irrespective of sputum status), or

- the cases were in the same setting at the same time when either was potentially infectious (9).

Possible links were recorded if;

- two cases were in the same place around the same time but the timing of when they were there or when they were infectious was not definite, or

- two cases worked in or were in the same place around the same time and shared social, occupational or behavioural characteristics that increased the chances of transmission, or

- two cases were in the same place at the same time but both had non-pulmonary TB, or

- one case volunteered the name of the other as a contact but both had non-pulmonary TB (9).

Probable or definite transmission was deemed to have occurred in a ST cluster if known or possible epidemiological links were identified linking members of the cluster, good evidence that they were involved in the same chain of recent transmission (9).

Public health action was defined as any action undertaken in addition to standard contact tracing, e.g. extended contact tracing and screening of new contacts in response to the cluster or any other actions undertaken that would constitute public health action such as awareness raising of TB signs and symptoms. 
The timing of the knowledge of the existence of epidemiological links existing between members of the cluster was categorised as either;

- prior to cluster investigation if the epidemiological link was already known to the public health professionals or,

- as a consequence of cluster investigation if the link between two cases in a cluster was elucidated during the process of cluster investigation.

Clusters may include both epidemiological links known prior to cluster investigation and links found as a consequence of cluster investigation.

Equally the timing of public health action being undertaken was categorised as either prior to or as a consequence of molecular cluster investigation. For example, if two cases were linked in time and place during standard contact tracing which resulted in extended contact tracing being undertaken in the setting identified, this would be public health action prior to cluster investigation. 


\section{Results}

\section{Cluster Investigations}

There were 278 TB ST Cls in England from 1 January 2010 to 30 June 2013 involving 1882 TB cases with cluster size ranging from 2 to 92 (median 6). A Cl Outcome Form was completed for every investigation initiated, a $100 \%$ response rate.

Cluster investigations were most frequently $(n=150,54 \%)$ initiated within a local health protection team, $37 \%(n=104)$ were national and $9 \%(n=24)$ within a region. Forty percent $(n=111)$ of $\mathrm{Cls}$ were initiated because the pre-determined threshold for investigation was reached. In $27 \%$ ( $n=76$ ), $\mathrm{Cl}$ were undertaken because at least one case in the cluster had RFs, with drug and/or alcohol misuse being the most commonly occurring risk factors. In $8 \%$ clusters were investigated due to the inclusion of a healthcare worker $(n=21)$ and in $7 \%$ due to the cluster containing a child $(n=20)$ (Table 1$)$. There were a number of other reasons clusters were investigated below the set threshold, these included geographical proximity of cases, cluster containing individuals with resistance to one or more first line drugs and cases all having the same ethnicity or country of birth. A review meeting was held for nearly all $\mathrm{Cls}$ $(n=275)$ and a meeting of the incident control team involving allied professionals for nearly a quarter $(n=61)$. In 9\% of $\mathrm{Cls}(n=25)$ additional typing at PHE Mycobacterial Reference Laboratories to further differentiate cases was requested, both typing of historical isolates which were only previously typed to 12 loci, or further typing of isolates to 32 loci.

\section{Epidemiological Links Identified}

Epidemiological links were identified in $66 \%(n=184)$ of clusters investigated. Of these clusters with epidemiological links established, $55 \%$ ( $n=101$ clusters) had epidemiological links as a result of the $\mathrm{Cl}(26 \%$ as a consequence of the $\mathrm{Cl}$ and $29 \%$ both as a consequence of and prior to the $\mathrm{Cl}$ ) and $45 \%(\mathrm{n}=83$ ) were known prior to the $\mathrm{Cl}$ (Figure 1). We estimated the added epidemiological value of $\mathrm{Cls}$ as $36 \%(101 / 278)$ in terms of identifying new epidemiological links in clusters.

In 26 (9\%) Cls, epidemiological links were found to exist between all members of the cluster. The median size of these clusters were three cases.

In $18 \%$ of clusters ( $n=49$ ), ST results showed cases previously determined, during routine TB contact tracing activities, to be epidemiologically linked, had strains with discordant MIRUVNTR patterns therefore refuting transmission.

Epidemiological links were identified in $69 \%(n=103)$ of local Cls (half of which were identified as a consequence of the $\mathrm{Cl}$ ), $61 \%(\mathrm{n}=63$ ) of national investigations, (of which $62 \%$ were as a result of the $\mathrm{Cl}$ ) and $75 \%(\mathrm{n}=18)$ of regional investigations (of which $56 \%$ were as a result of the $\mathrm{Cl}$ ) (Table 1). 
In clusters investigated because the predefined threshold was reached nearly $80 \%$ had epidemiological links identified, of which $53 \%$ were as a consequence of the $\mathrm{Cl}$. In clusters investigated because they contained individuals with RFs for transmission, $57 \%$ had epidemiological links identified ( $53 \%$ of which were as a consequence of the $\mathrm{Cl}$ ). In cluster investigations initiated because they contained a healthcare worker, $43 \%$ had epidemiological links identified within the cluster but not necessarily with the healthcare worker, $156 \%$ of which were as a consequence of the $\mathrm{Cl}$ ). In those investigated because they contained a child $60 \%$ had epidemiological links identified (of which $58 \%$ were as a consequence of the $\mathrm{Cl}$ ) (Table1).

\section{Public Health Actions Taken}

Public health action was reportedly undertaken (in addition to standard contact tracing) in 91 (46\%) of $200 \mathrm{Cls}$ with this information. In $34(37 \%)$ this was as a consequence of the $\mathrm{Cl}$; in 46 (51\%) sufficient public health action had already been undertaken prior to the $\mathrm{Cl}$ and in 11 (12\%) action was taken both prior to, and as a consequence of, the $\mathrm{Cl}$ (Figure 2). Overall we found $23 \%(45 / 200)$ of clusters had additional public health actions undertaken as a consequence of $\mathrm{Cls}$ (Table 2).

In twelve out of these 45 clusters where public health action was undertaken as a consequence of the $\mathrm{Cls}$, the number of additional cases identified was reported. Overall 1517 additional contacts were identified and screened (628 from one cluster) following cluster investigation, this led to the identification of 23 active and 136 latent cases.

In Cls initiated because of reaching the predefined threshold, $43 \%$ resulted in additional public health action being undertaken as a consequence of the $\mathrm{Cl}$ compared to $75 \%$ of those initiated because they contained individuals with RFs for transmission (Table 2).

\section{Occurrence of Transmission}

Transmission occurred more often in large compared to small clusters (82\% in large clusters, $47 \%$ in small clusters) ( $p<0.05)$ and additional public health action, as a consequence of $\mathrm{Cl}$, was more likely to be undertaken in large compared to small clusters ( $51 \%$ in large clusters, $30 \%$ in small clusters) $(p<0.05)$ (Table 1,2$)$.

Probable or definite transmission was reported to have occurred in 180 (65\%) Cls, no apparent transmission in 73 (26\%), investigations were inconclusive in 16 (6\%) and in 9 (3\%) investigations were ongoing (Table 1 ).

Health protection staff who responded to the question $(n=187)$ stated what factors they believed contributed to transmission; in $63 \%(n=117)$ of Cls no factors were identified, in $14 \%$ $(n=27)$ transmission was considered to have occurred due to inadequate identification of, and screening of, contacts of early cases, in $9 \%(n=16)$ transmission was reportedly due to a lack 
of co-operation with contact tracing of the early cases in the cluster, $8 \%(n=15)$ due to delayed diagnosis of early cases and $6 \%(n=12)$ for other reasons.

\section{Utility of ST information}

The ST data was deemed useful by public health staff leading the investigations in nearly $80 \%$ of investigations, where reported (207/260). 


\section{Discussion and Conclusions}

We report a high level of potential benefit to local health professionals of molecular TB straintyping in England. Our study during 2010 to 2013 showed that 278 clusters were investigated and new epidemiological links were identified in $36 \%$ of clusters, resulting in additional public health action being undertaken in $23 \%$ of clusters and in $18 \%$ of clusters, investigation refuted links previously thought to exist.

This proportion of new epidemiological links discovered is comparable to the $38-57 \%$ of epidemiological linkages identified in clusters (varying on strength of epidemiological association) across four sentinel sites in the United States of America (USA) in 1998-2000(10). Although their proportion was based on cluster pairs and a different molecular method, restriction fragment length polymorphism (RFLP), was used. Similarly in the Netherlands, also using the RFLP molecular method, researchers found that $31 \%$ of clustered cases had a new epidemiological link established after cluster feedback (11).

The proportion of clusters with true epidemiological links between cases may be higher than identified. Cases may deliberately or innocently withhold information regarding links to others, particularly those with prison history or problems with drug misuse due to the misconception of implication in potential illegal activities; this can result in ongoing transmission in specific populations and a failure to identify the connection between cases $(12,13)$.

In $18 \%$ of clusters, investigation refuted links previously thought to exist. This is very useful since it enables limited public health resources to be targeted elsewhere. Research from the USA reports that $29 \%$ of links identified and thought to exist during standard contact tracing were disproved after molecular typing became available $(10,14)$. Conversely the Netherlands research reported that just $5 \%$ of links identified prior to the availability of molecular information were disproved (11). The validity of comparisons remains problematic however due to the use of different molecular techniques and should be further explored with differing definitions of a cluster. Additionally the use of more sophisticated laboratory methods, such as whole genome sequencing which has been shown to have a higher discriminatory power (15), to determine clustering will be key in further understanding the evidence for transmission.

The time taken for culture diagnosis, DNA extraction, performance of and receipt of ST results inevitably leads to a delay in $\mathrm{Cl}$ initiation and lost opportunity for any additional public health action. Early cases in a cluster are likely to have completed treatment and can be difficult to trace again to interview as part of an investigation (14). The challenge of minimising delays in diagnosis of TB cases by identifying and screening contacts was highlighted as the main factor to have contributed to cluster growth in more than one in five clusters. Following a comprehensive evaluation it has been reported that the TB-STS had no significant effect on reducing diagnostic delay (16). However this evaluation utilised data from the early part of 
the service, the first three years, therefore it was less likely to find evidence. Work in the USA indicated that linkages discovered only during cluster investigation were more likely to be in non-traditional settings (defined as those not including home, school, workplace and common congregate settings such as correctional facilities, day-care centres nursing homes) and nontraditional relationships (defined as to not include household, friend and co-worker contacts) $(10,17)$ than during conventional contact tracing. We recommend that sufficient time is given for interviews with patients to build rapport and enable effective contact tracing to be carried out so that epidemiological links can be established and any foci for enhanced transmission identified. In addition investment should be made in epidemiological skill training and capacity building to enhance investigation skills.

If limited public health resources are to be targeted well, then clusters where there is the greatest potential for added public health value need to be prioritised for investigation. The proportion of $\mathrm{Cls}$ with new links identified was $42 \%$ in those investigated because the threshold for investigation was reached, which translated to additional public health action being undertaken in $21 \%$ of these. New epidemiological links were identified in $35 \%$ of clusters containing a child or children with additional public health action in $16 \%$, and $30 \%$ in clusters containing individuals with risk factors resulting in additional public health action reportedly being undertaken in $44 \%$ of these clusters. We recommend clusters with these characteristics be prioritised for investigation on the basis of likely higher yield of previously unknown epidemiological links. The additional knowledge gained on the basis of ST CI has previously been reported as limited (7). While additional public health action being undertaken as a result of strain type cluster investigations for only $23 \%$ of clusters may initially appear low, if this additional action led to a reduction in TB transmission, it may have led to public health benefit.

\section{Limitations}

The existence of epidemiological links were locally determined. We were unable to validate epidemiological links stated to exist nor to confirm the exact timing of any public health interventions in relation to timing of receipt of ST results. Further, the unit of investigation was cluster, rather than case, therefore it was not defined who within the cluster the epidemiological links were between. Future work should investigate the nature of the epidemiological links and describe them in more detail. We were only able to establish if public health actions taken led to the identification and treatment of additional cases of latent TB infection or active TB in a limited number of clusters. This information needs to be better collected in the future as evidence for prevention of further transmission.

Quantifying the added epidemiological value in prospective strain typing cluster investigations is not straightforward. Although a standard method of investigation was recommended in England (in the national strain typing handbook) (9) we know that there were variations in intensity of investigation which could have led to a detection bias in 
determining epidemiological links. Funding was not provided, as part of the TB-STS, to the NHS TB Services for any extra workload resulting from gathering additional information from patients as part of cluster investigations. There is the possibility that with additional resources further epidemiological links may have been elucidated due to the additional time an individual could spend investigating the cluster. We believe it is likely, therefore, that the estimates of clusters with true epidemiological links found as a result of cluster investigations are an under- rather than an over- estimation. We recommend that cluster investigations are carried out and actions and outcomes should continue to be recorded in a systematic manner to ensure continued public health review and quality assurance.

The usefulness of strain typing information was a personal opinion of the public health workers leading the investigation, it was subjective and therefore difficult to measure the interpretation. This has previously been reported as high (18).

Given the level of resolution of genetic relatedness provided by MIRU-VNTR, clustering does not necessarily signify recent transmission (19-21), as some MIRU-VNTR clusters investigated will have been false positive transmission clusters. The higher level of resolution provided by Whole Genome Sequencing (WGS) of TB strains should increase the utility of cluster investigation (18). In addition, it is hoped that WGS will increase the timeliness of molecular characterisation of strains from the laboratory perspective which should improve the speed with which public health action can be initiated (19).

\section{Conclusion}

We found positive benefits in both TB molecular strain typing and cluster investigation in England. Both in terms of identifying new epidemiological links between cases and taking public health action, and conversely in refuting transmission and saving limited public health resources. The public health benefit is evidenced in the reported cases identified following cluster investigations however the additional public health benefit in terms of reduced onward transmission of TB needs further quantification in order to provide convincing evidence of public health value.

Indicators of such benefit might include reduced diagnostic delay through earlier identification of active cases (shortened intervals from onset to diagnosis or treatment of those contacts who are found to have active TB), through contact investigations in strain type cluster investigations compared to other active cases detected through routine contact tracing, as well as higher rates of LTBI detection and prophylaxis. 


\section{Acknowledgments}

We would like to thank; the PHE TB Strain Typing Project Board (Prof John Watson, Dr Philip Monk, Prof Francis Drobniewski, Prof John Magee, Dr Grace Smith), Claire Catherall, Shanel Reshat and Natasha Ratna for administrative support, the NHS TB services for completion of cluster questionnaires and participation in cluster investigations, local health protection team TB leads for support to the TB Strain Typing Service, all those who completed cluster outcome forms and Regional TB leads for encouraging their return. 


\section{References}

1. Public Health England. Tuberculosis in England. 2016 report version 1.1. [Internet]. London: Public Health England; 2016. Available from: https://www.gov.uk/government/publications/tuberculosis-in-england-annual-report

2. European Centre for Disease Prevention and Control. Tuberculosis surveillance and monitoring in Europe 2013. [Internet]. Stockholm: European Centre for Disease Prevention and Control; 2013. Available from: http://www.ecdc.europa.eu/en/publications/_layouts/forms/Publication_DispForm.aspx?Lis $\mathrm{t}=4 \mathrm{f5} 5 \mathrm{ad51}-4$ aed-4d32-b960-af70113dbb90\&ID=811

3. Centers for Disease Control and Prevention. Trends in Tuberculosis - United States, 2012. MMWR. 2013 Mar 22;62(11):201-2.

4. Department of Health. Stopping Tuberculosis in England: An Action Plan from the Chief Medical Officer. 2004. London, Department of Health http://www.hpa.org.uk/Topics/InfectiousDiseases/InfectionsAZ/Tuberculosis/NationalTuber culosisStrainTypingService/

5. CDC. Tuberculosis Genotyping in the United States, 2004-2010. Atlanta, GA:

U.S. Department of Health and Human Services, CDC, June 2012.

6. van Soolingen D, Borgdorff MW, de Haas PE, Sebek MM, Veen J, Dessens M, Kremer K, van Embden JD. Molecular epidemiology of tuberculosis in the Netherlands: a nationwide study from 1993 through 1997. J Infect Dis. 1999 Sep;180(3):726-36.

7. J. Bauer, A. Kok-Jensen, P. Faurschou, J. Thuesen, E. Taudorf, Å. B. Andersen A prospective evaluation of the clinical value of nation-wide DNA fingerprinting of tuberculosis isolates in Denmark. Int J. Tuberc Lung Dis 4(4):295-299

8. HPA Mycobacterium tuberculosis Strain Typing: A guide to data production and distribution. 2012 http://www.hpa.org.uk/webc/HPAwebFile/HPAweb_C/1317135835628

9. Public Health England TB Strain Typing and Cluster Investigation Handbook 3rd Edition London: Public Health England; 2014. Available from: http://www.hpa.org.uk/webc/HPAwebFile/HPAweb_C/1317140774833

10. S.J. N. McNabb, J. S. Kammerer, A. C. Hickey, C. R. Braden, N. Shang, L.S. Rosenblum, T.R. Navin Added Epidemiologic Value to Tuberculosis Prevention and Control of the Investigation of Clustered Genotypes of Mycobacterium tuberculosis Isolates Am J Epidemiol 2004;160:589-597

11. C. S. B. Lambregts-van Weezenbeek, M. M. G. G. Sebek, P. J. H. J. van Gerven, G. de Vries, S. Verver, N. A. Kalisvaart, D. van Soolingen. Tuberculosis contact investigation and DNA fingerprint surveillance in The Netherlands: 6 years' experience with nation-wide cluster feedback and cluster monitoring. Int J. Tuberc Lung Dis 7(12):S463-S470

12. Asghar, RJ, Patlan, DE, Miner, MC et al. Limited utility of name-based tuberculosis contact investigations among persons using illicit drugs: results of an outbreak investigation. J Urban Health.2009; 86: 776-780

13. Burki, T. Tackling tuberculosis in London's homeless population. Lancet. 2010; 376: 20552056

14. Bennett, DE, Onorato IM, Ellis BA, Crawford JT, Schable B, Byers R, Kammerer JS, Braden CR DNA fingerprinting of Mycobacterium tuberculosis isolates from epidemiologically linked cluster pairs. Emerg Infect Dis 2002;8:1224-9. 
15. Borgdorff MW, van Soolingen D. The re-emergence of tuberculosis: what have we learnt from molecular epidemiology? Clin Microbiol Infect. 2013; 19:10 889-901

16. Mears J, Vynnycky E, Lord J, Borgdorff MW, Cohen T, Crisp D, Innes JA, Lilley M, Maguire H, McHugh TD, Woltmann G, Abubakar I,Sonnenberg P. The prospective evaluation of the TB strain typing service in England: a mixed methods study . Thorax 2016;71:8 734741 Published Online First: 16 April 2015

17. Kammerer JS, McNabb SJN, Becerra JE, Rosenblum L, Shang N, Lademarco MF, Navin TR, Tuberculosis Transmission in Nontraditional Settings A Decision-Tree Approach Am J Prev Med 2005;28(2):201-207

18. Mears J, Abubakar I, Crisp D, Maguire H, Innes JA, Lilley M, Lord J, Cohen T, Borgdorff MW, Vynnycky E, McHugh TD, Sonnenberg P. Prospective evaluation of a complex public health intervention: lessons from an initial and follow-up cross sectional survey of the tuberculosis strain typing service in England. BMC Public Health 2014 14:1023

19. Walker TM, Ip CL, Harrell RH, Evans JT, Kapatai G, Dedicoat MJ, Eyre DW, Wilson DJ, Hawkey PM, Crook DW, Parkhill J, Harris D, Walker AS, Bowden R,Monk P, Smith EG, Peto TE. Wholegenome sequencing to delineate Mycobacterium tuberculosis outbreaks: a retrospective observational study. Lancet Infect Dis. 2013 Feb;13(2):137-46

20. Hamblion EL, Le Menach A, Anderson L, Lalor MK, Brown T, Abubakar I, Anderson C, Maguire $\mathrm{H}$, Anderson SR. Recent TB transmission, clustering and predictors of large clusters in London,2010-2012: results from first 3 years of universal MIRU-VNTR straintyping. Thorax 2016 Aug;71(8):749-56. doi: 10.1136/thoraxjnl-2014-206608

21. Mears J, Abubakar I, Cohen T, McHugh TD, Sonnenberg P.Effect of study design and setting on tuberculosis clustering estimates using Mycobacterial Interspersed Repetitive UnitsVariable Number Tandem Repeats (MIRU-VNTR): a systematic review. BMJ Open. 2015 Jan 21;5(1):e005636 


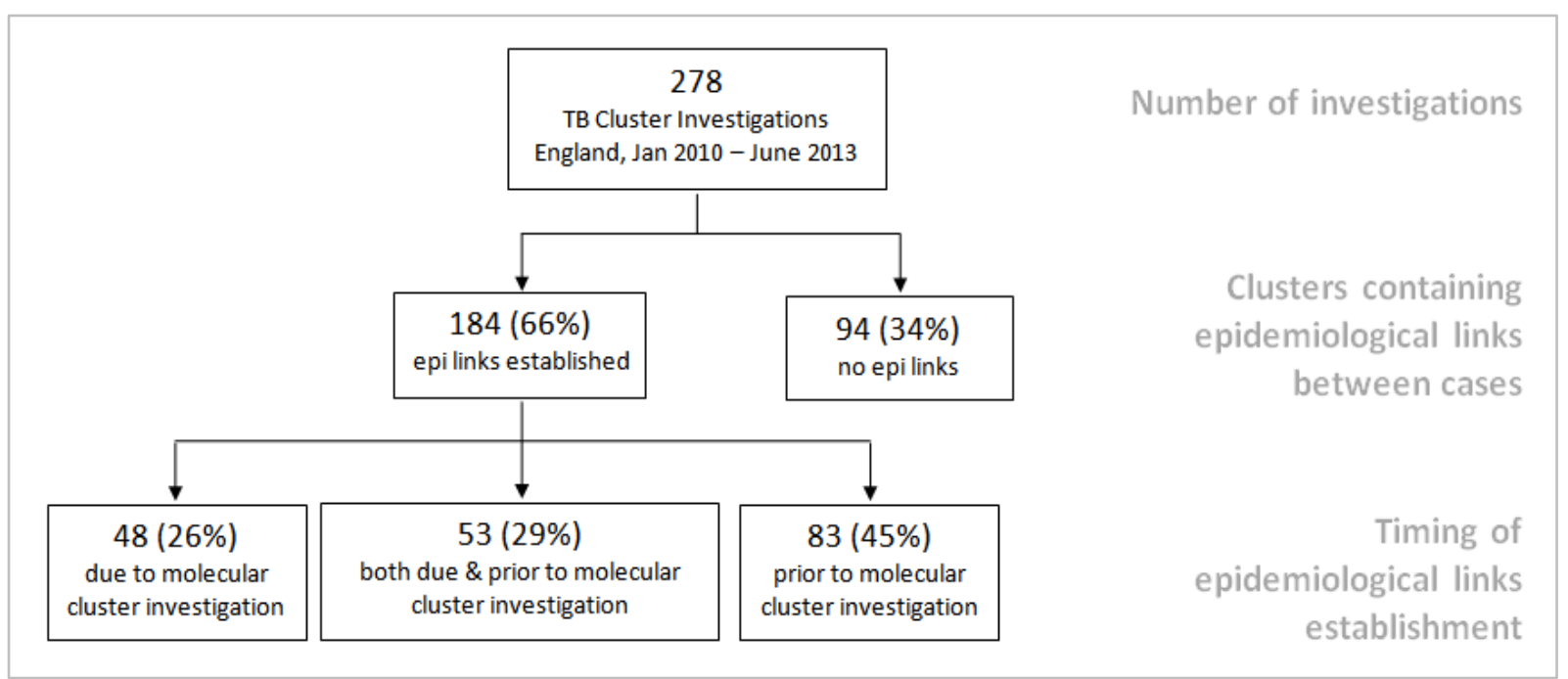

Figure 1: Cluster investigations carried out, epidemiological links reportedly identified as a consequence of or prior to Strain Typed Cluster Investigations, TB Strain Typing Outcomes England January 2010- June 2013

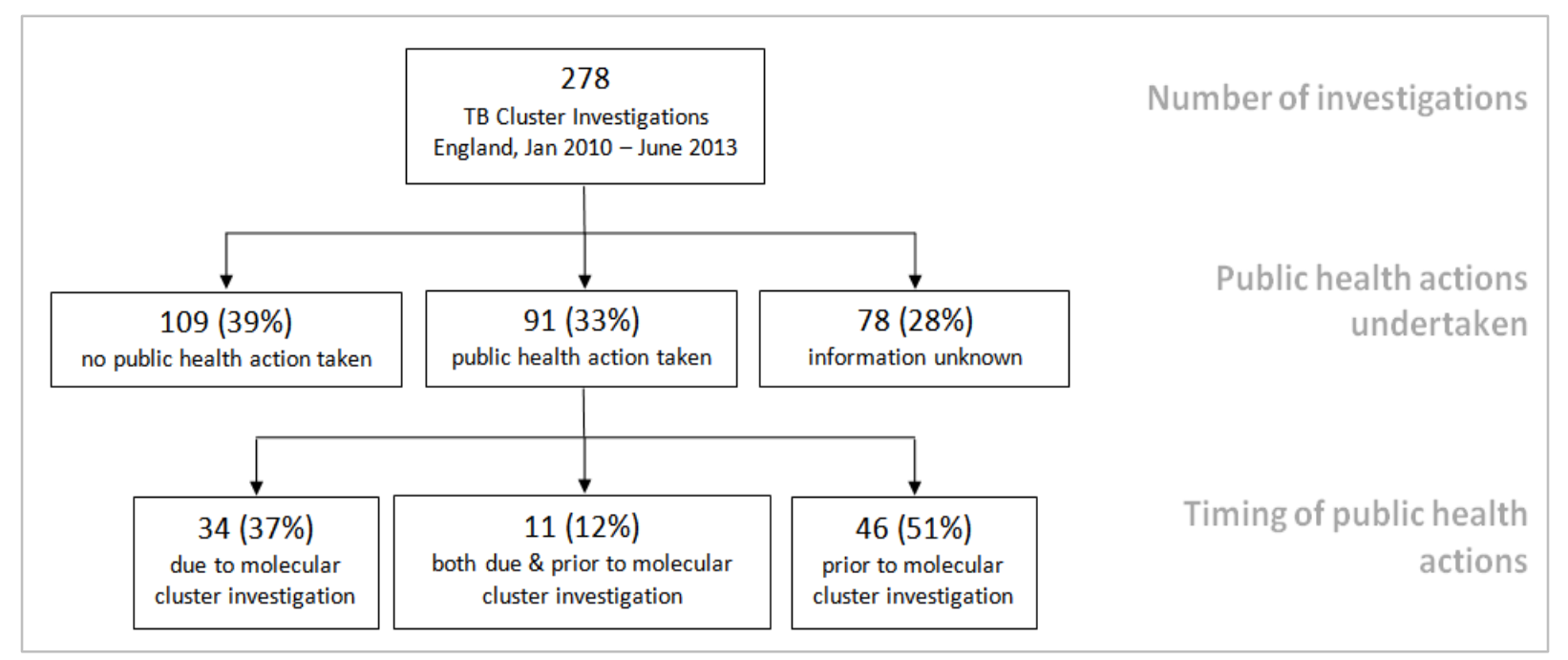

Figure 2: Cluster investigations carried out, public health action taken as a consequence of or prior to Strain Typed Cluster Investigations, TB Strain Typing Outcomes England January 2010- June 2013 


\begin{tabular}{|c|c|c|c|c|c|}
\hline Variable & $\begin{array}{l}\text { Total no. } \\
\text { of clusters }\end{array}$ & $\begin{array}{l}\text { Percentage (no.) of } \\
\text { clusters with epi } \\
\text { links established }\end{array}$ & $\begin{array}{l}\text { Percentage (no.) links } \\
\text { found due to } \mathrm{Cl} \text { (of } \\
\text { those with epi links) }\end{array}$ & $\begin{array}{l}\text { Added epidemiological } \\
\text { value of cluster } \\
\text { investigations }\end{array}$ & $\begin{array}{l}\text { Percentage (no.) with } \\
\text { probable or definite } \\
\text { transmission }\end{array}$ \\
\hline All cluster investigations & 278 & $66 \%(184)$ & $55 \% \quad(101)$ & $36 \%$ & $65 \%(180)$ \\
\hline \multicolumn{6}{|l|}{ Geographical footprint of investigation } \\
\hline Local & 150 & $69 \%(103)$ & $50 \% \quad(52)$ & $35 \%$ & $67 \%(100)$ \\
\hline Regional & 24 & $75 \% \quad(18)$ & $56 \% \quad(10)$ & $42 \%$ & $75 \% \quad(18)$ \\
\hline National & 104 & $61 \%(63)$ & $62 \% \quad(39)$ & $38 \%$ & $60 \% \quad(62)$ \\
\hline \multicolumn{6}{|l|}{ Size of cluster investigated } \\
\hline Small (2-4 cases) & 100 & $48 \% \quad(48)$ & $52 \% \quad(25)$ & $25 \%$ & $47 \% \quad(47)$ \\
\hline Medium (5-9 cases) & 91 & $69 \% \quad(63)$ & $54 \% \quad(34)$ & $37 \%$ & $68 \%(62)$ \\
\hline Large ( $\geq 10$ cases) & 87 & $84 \% \quad(73)$ & $58 \% \quad(42)$ & $48 \%$ & $82 \% \quad(71)$ \\
\hline \multicolumn{6}{|l|}{ Reason cluster investigated } \\
\hline Threshold reached & 111 & $79 \% \quad(88)$ & $53 \% \quad(47)$ & $42 \%$ & $77 \% \quad(86)$ \\
\hline Contained individual(s) with risk factors & 76 & $57 \% \quad(43)$ & $53 \% \quad(23)$ & $30 \%$ & $55 \% \quad(42)$ \\
\hline Contained HCW(s) & 21 & $43 \% \quad$ (9) & $56 \% \quad(5)$ & $24 \%$ & $43 \% \quad$ (9) \\
\hline Contained Child(ren) & 20 & $60 \% \quad(12)$ & $58 \% \quad$ (7) & $35 \%$ & $55 \%(11)$ \\
\hline Other & 50 & $64 \% \quad$ (32) & $59 \%$ (19) & $38 \%$ & $64 \%$ (32) \\
\hline
\end{tabular}

Table 1: Number and percentage of clusters investigated, with epidemiological links identified, the resulting added epidemiological value and transmission thought to have occurred according to geographical footprint, size of cluster, and reason for the cluster investigation, TB Strain Typing Outcomes England January 2010- June 2013 


\begin{tabular}{|c|c|c|c|c|}
\hline Variable & $\begin{array}{l}\text { Total no. of } \\
\text { clusters }\end{array}$ & $\begin{array}{l}\text { No. of clusters with } \\
\text { information on public } \\
\text { health actions taken* }\end{array}$ & $\begin{array}{l}\text { Percentage (no.) of } \\
\text { clusters where public } \\
\text { health action undertaken }\end{array}$ & $\begin{array}{l}\text { Percentage (no.) of clusters } \\
\text { with additional public health } \\
\text { action taken due to } \mathrm{Cl}\end{array}$ \\
\hline All cluster investigations & 278 & 200 & $46 \%(91)$ & $23 \%(45)$ \\
\hline \multicolumn{5}{|l|}{ Geographical footprint of investigation } \\
\hline Local & 150 & 150 & $41 \%(61)$ & $14 \%(21)$ \\
\hline Regional & 24 & 24 & $33 \% \quad(8)$ & $8 \%(2)$ \\
\hline National & 104 & 26 & $85 \% \quad(22)$ & $85 \%(22)$ \\
\hline \multicolumn{5}{|l|}{ Size of cluster investigated } \\
\hline Small (2-4 cases) & 100 & 76 & $38 \% \quad(29)$ & $30 \%(12)$ \\
\hline Medium (5-9 cases) & 91 & 67 & $48 \% \quad(32)$ & $36 \%(14)$ \\
\hline Large ( $\geq 10$ cases) & 87 & 57 & $53 \% \quad(30)$ & $51 \%(19)$ \\
\hline \multicolumn{5}{|l|}{ Reason cluster investigated } \\
\hline Threshold reached & 111 & 91 & $48 \% \quad(44)$ & $21 \%(19)$ \\
\hline Contained individual(s) with risk factors & 76 & 34 & $59 \% \quad(20)$ & $44 \%(15)$ \\
\hline Contained HCW(s) & 21 & 19 & $21 \% \quad(4)$ & $11 \%(2)$ \\
\hline Contained Child(ren) & 20 & 19 & $47 \% \quad$ (9) & $16 \%(3)$ \\
\hline Other & 50 & 37 & $38 \% \quad(14)$ & $16 \%(6)$ \\
\hline
\end{tabular}

* information unknown for 78 clusters

Table 2: Number and percentage of clusters investigated, with public health action taken and the resulting added public health value according to geographical footprint, size of cluster and reason for the cluster investigation, TB Strain Typing Outcomes England January 2010- June 2013 